\title{
Cytochrome oxidase I sequences reveal possible cryptic diversity in the cosmopolitan symbiotic copepod Nesippus orientalis Heller, 1868 (Pandaridae: Siphonostomatoida) on elasmobranch hosts from the KwaZulu-Natal coast of South Africa
}

\author{
Susan M. Dippenaar ${ }^{\mathrm{a}, *}$, Rosaline B. Mathibela ${ }^{\mathrm{a}, 1}$, Paulette Bloomer $^{\mathrm{b}}$ \\ a Department of Biodiversity, SMLS, University of Limpopo, P/Bag X1106, Sovenga 0727, South Africa \\ ${ }^{\mathrm{b}}$ Molecular Ecology and Evolution Programme, Department of Genetics, University of Pretoria, Pretoria 0002, South Africa
}

\section{A R T I C L E I N F O}

\section{Article history:}

Received 11 March 2009

Received in revised form 14 August 2009

Accepted 26 August 2009

Available online $\mathrm{xxxx}$

\section{Keywords:}

Nesippus orientalis

Cytochrome oxidase I

Siphonostomatoida

Copepoda

Cryptic diversity

Elasmobranchs

Sharks

Sphyrna

Carcharhinus

Carcharodon

Isurus

Carcharias

South Africa

\begin{abstract}
A B S T R A C T
Over the past decade, numerous molecular phylogenetic studies uncovered cryptic diversity within the Copepoda, yet very few investigations focused on symbiotic copepods. Here we report mitochondrial DNA cytochrome oxidase I diversity in the cosmopolitan elasmobranch symbiont Nesippus orientalis off the KwaZulu-Natal coast of South Africa. Analysis of partial COI sequences of copepods sampled from a diversity of shark hosts, revealed the presence of two divergent clades. Diversity within the clades does not appear to be structured based on host species, host individual, geographic locality or time of sampling. However, divergence between the two clades seems to be related to host species. Phylogenetic analyses of representatives from the two clades, along with Nesippus spp., Caligus spp. and Lepeophtheirus spp. outgroups, further supports the distinction between the two clades. Future molecular phylogenetic investigations of widespread copepod symbionts most likely will reveal far greater levels of biodiversity than currently recognized.
\end{abstract}

(c) 2009 Elsevier Inc. All rights reserved.

\section{Introduction}

The genus Nesippus Heller, 1868 includes five nominal species, i.e. N. orientalis Heller, 1868; N. crypturus Heller, 1868; N. vespa Kirtesinghe, 1964; N. tigris Cressey, 1967 and N. nana Cressey, 1970 (Boxshall and Halsey, 2004; Cressey, 1967, 1970). All species are cosmopolitan in their distribution and occur in the mouths, on the gill arches and in the nasal passages of a variety of elasmobranch hosts (Cressey, 1967, 1970; Dippenaar and Jordaan, 2006).

Nesippus orientalis can be easily distinguished from the other species by the presence of dorsal plates on the fourth thoracic segment (Cressey, 1967). They are commonly found on a number of shark species (Cressey, 1967, 1970; Dippenaar, 2004; Dippenaar

\footnotetext{
* Corresponding author. Tel.: +27 152683112.

E-mail address: susand@ul.ac.za (S.M. Dippenaar).

${ }^{1}$ Fax: +27 152682976 .
}

and Jordaan, 2006), often in clusters on the gill arches and in the mouth (Dippenaar and Jordaan, 2006).

The life cycle of $N$. orientalis is unknown, however, Wilson (1907) already stated that the life cycles of representatives of Pandaridae are similar to those of the Caligidae and this suggestion is strengthened by the monophyletic grouping of Pandaridae and Caligidae (Huys et al., 2007; Dippenaar, 2009). The general life cycle of caligids consists of two free-living nauplius stages, followed by one infective copepodid stage and four parasitic chalimus stages, two parasitic preadult stages and the parasitic adults (Kabata, 1981). Even though small deviations from the general life cycle are found (see Lin and Ho, 1993), information about their life cycles (see Lin and Ho, 1993; Schram, 1993; Todd, 2007) can be used to deduce that the life cycle of $N$. orientalis individuals likely comprise a short free-living phase, while all other stages will be attached to a host. Information about the biology of members of the Caligidae (see Boxshall, 1974; Anstensrud, 1990; Todd, 2007) can be used to speculate that males of $N$. orientalis can probably

0014-4894/\$ - see front matter (c) 2009 Elsevier Inc. All rights reserved.

doi:10.1016/j.exppara.2009.08.017 
copulate with several females, while the females may be polyandrous. Individuals of $N$. orientalis attach to the gill arches and in the mouth of their hosts and the females in particular do not seem to move vast distances due to their orderly way of attachment (Dippenaar and Jordaan, 2006). Based on these observations and the occurrence of young among adults (Dippenaar and Jordaan, 2006), it thus appears unlikely that they would move from one host to another, even when hosts come into physical contact with one another.

Since it is impractical to track the planktonic stages of marine invertebrate larvae in the water column (Todd, 1998), especially of those species that as adults live symbiotically on elasmobranch hosts, analyses of the degree and scale of genetic differentiation among populations offer an indirect method of accessing the scale of larval dispersal (Todd, 1998). Knowlton (1993, 2000) also recognized the potential of molecular genetics to identify sibling or cryptic species (i.e. species difficult to distinguish using traditional techniques), which often exist among members of the Crustacea and Copepoda (see e.g. Burton and Lee, 1994; Bucklin et al., 1999; Rocha-Olivares et al., 2001). In this respect, mitochondrial genomes contain markers suitable for studies of population genetics and evolution (Shao and Barker, 2007), with the cytochrome $c$ oxidase subunit I (COI) gene reported to be successfully employed for species recognition (Hebert et al., 2003; Waugh, 2007). Even though $\mathrm{COI}$ markers get saturated quickly around 0.3 substitutions per site, determined with uncorrected pairwise distances, a fairly good approximation can still be made to delimit species using this method (Lefébure et al., 2006). Under the phylogenetic species definition, the COI gene has a proposed species delimitation threshold of 0.16 substitutions per site in crustaceans (Lefébure et al., 2006), and has proven to be specifically efficient in copepods (Bucklin et al., 1999; Hill et al., 2001; Øines and Heuch, 2005).

Few studies have been conducted to assess the genetic variation within and between populations of symbiotic siphonostomatoids. A study on the genetic heterogeneity within populations of Lepeophtheirus europaensis Zeddam, Berrebi, Renaud, Raibaut and Gabrion, 1988 parasitic on two host species, reported incipient sympatric speciation (De Meeüs et al., 1992). More recent studies on Caligus elongatus Nordmann, 1832 revealed the presence of two distinct genotypes possibly distinguishing two sibling species

Table 1

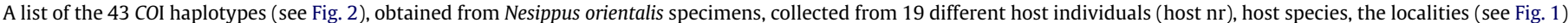
where the hosts were caught, the dates when they were caught and their GenBank accession Nos.

\begin{tabular}{|c|c|c|c|c|c|c|}
\hline Haplotype & Host nr & Shark species & Locality & Coordinates & Date caught & GenBank Accession Nos. \\
\hline \multicolumn{7}{|l|}{ Clade I } \\
\hline GHDN01 & 1 & Sphyrna mokarran & Durban & $29.51 \mathrm{~S} 31.00 \mathrm{E}$ & $11 / 2000$ & GQ369463 \\
\hline GHDNO2 & 1 & Sphyrna mokarran & Durban & $29.51 \mathrm{~S} 31.00 \mathrm{E}$ & $11 / 2000$ & GQ369464 \\
\hline GHDN03 & 1 & Sphyrna mokarran & Durban & $29.51 \mathrm{~S} 31.00 \mathrm{E}$ & $11 / 2000$ & GQ369465 \\
\hline BTRB01 & 2 & Carcharhinus limbatus & Richards Bay & $28.48 \mathrm{~S} 32.06 \mathrm{E}$ & $10 / 2002$ & GQ369466 \\
\hline BTRB02 & 2 & Carcharhinus limbatus & Richards Bay & $28.48 \mathrm{~S} 32.06 \mathrm{E}$ & $10 / 2002$ & GQ369467 \\
\hline BTRB03 & 2 & Carcharhinus limbatus & Richards Bay & $28.48 \mathrm{~S} 32.06 \mathrm{E}$ & $10 / 2002$ & GQ369468 \\
\hline ZMRB01 & 3 & Carcharhinus leucas & Richards Bay & $28.48 \mathrm{~S} 32.06 \mathrm{E}$ & $10 / 2002$ & GQ369469 \\
\hline ZMRB02 & 3 & Carcharhinus leucas & Richards Bay & $28.48 \mathrm{~S} 32.06 \mathrm{E}$ & $10 / 2002$ & GQ369470 \\
\hline \multicolumn{7}{|l|}{ Clade II } \\
\hline GWRB01 & 4 & Carcharodon carcharias & Richards Bay & $28.48 \mathrm{~S} 32.06 \mathrm{E}$ & $10 / 2002$ & GQ369471 \\
\hline RTRB03 & 5 & Carcharias taurus & Richards Bay & $28.48 \mathrm{~S} 32.06 \mathrm{E}$ & 11/1999 & GQ369480 \\
\hline CHPE01 & 6 & Sphyrna lewini & Port Edward & $31.03 \mathrm{~S} 30.14 \mathrm{E}$ & $06 / 1998$ & GQ369502 \\
\hline CSMG02 & 7 & Carcharhinus brachyurus & Margate & $30.52 \mathrm{~S} 30.21 \mathrm{E}$ & $11 / 2004$ & GQ369505 \\
\hline GWLB01 & 8 & Carcharodon carcharias & Leisure Bay & $31.01 \mathrm{~S} 30.14 \mathrm{E}$ & 03/1999 & GQ369474 \\
\hline RTRB06 & 10 & Carcharias taurus & Richards Bay & $28.48 \mathrm{~S} 32.06 \mathrm{E}$ & $11 / 1997$ & GQ369483 \\
\hline RTRB02 & 5 & Carcharias taurus & Richards Bay & $28.48 \mathrm{~S} 32.06 \mathrm{E}$ & 11/1999 & GQ369479 \\
\hline RTRB04 & 5 & Carcharias taurus & Richards Bay & $28.48 \mathrm{~S} 32.06 \mathrm{E}$ & 11/1999 & GQ369481 \\
\hline RTSB03 & 11 & Carcharias taurus & Scottburgh & $30.17 \mathrm{~S} 30.45 \mathrm{E}$ & $11 / 2002$ & GQ369492 \\
\hline GWRB03 & 4 & Carcharodon carcharias & Richards Bay & $28.48 \mathrm{~S} 32.06 \mathrm{E}$ & $10 / 2002$ & GQ369473 \\
\hline GWLB03 & 8 & Carcharodon carcharias & Leisure Bay & $31.01 \mathrm{~S} 30.14 \mathrm{E}$ & 03/1999 & GQ369476 \\
\hline RTRB09 & 12 & Carcharias taurus & Richards Bay & $28.48 \mathrm{~S} 32.06 \mathrm{E}$ & 11/1999 & GQ369486 \\
\hline RTRB01 & 5 & Carcharias taurus & Richards Bay & $28.48 \mathrm{~S} 32.06 \mathrm{E}$ & 11/1999 & GQ369478 \\
\hline RTZN01 & 13 & Carcharias taurus & Zinkwazi & $29.12 \mathrm{~S} 31.27 \mathrm{E}$ & $10 / 1998$ & GQ369493 \\
\hline SHDN01 & 14 & Sphyrna zygaena & Durban & $29.51 \mathrm{~S} 31.00 \mathrm{E}$ & $10 / 2002$ & GQ369500 \\
\hline GWLB02 & 8 & Carcharodon carcharias & Leisure Bay & $31.01 \mathrm{~S} 30.14 \mathrm{E}$ & 03/1999 & GQ369475 \\
\hline SFSR02 & 9 & Isurus oxyrinchus & Salt Rock & $29.30 \mathrm{~S} 31.15 \mathrm{E}$ & $11 / 2002$ & GQ369495 \\
\hline RTSB02 & 11 & Carcharias taurus & Scottburgh & $30.17 \mathrm{~S} 30.45 \mathrm{E}$ & $11 / 2002$ & GQ369491 \\
\hline RTRB10 & 12 & Carcharias taurus & Richards Bay & $28.48 \mathrm{~S} 32.06 \mathrm{E}$ & $11 / 1999$ & GQ369487 \\
\hline SHDN02 & 14 & Sphyrna zygaena & Durban & $29.51 \mathrm{~S} 31.00 \mathrm{E}$ & $10 / 2002$ & GQ369501 \\
\hline RTRB07 & 10 & Carcharias taurus & Richards Bay & $28.48 \mathrm{~S} 32.06 \mathrm{E}$ & $11 / 1997$ & GQ369484 \\
\hline RTRB11 & 12 & Carcharias taurus & Richards Bay & $28.48 \mathrm{~S} 32.06 \mathrm{E}$ & $11 / 1999$ & GQ369488 \\
\hline SHAB01 & 15 & Sphyrna zygaena & Anstey's Beach & $29.55 \mathrm{~S} 31.01 \mathrm{E}$ & $11 / 2002$ & GQ369497 \\
\hline SHMZ01 & 16 & Sphyrna zygaena & Mzamba & $31.05 \mathrm{~S} 30.10 \mathrm{E}$ & $08 / 1995$ & GQ369499 \\
\hline RTRB05 & 5 & Carcharias taurus & Richards Bay & $28.48 \mathrm{~S} 32.06 \mathrm{E}$ & 11/1999 & GQ369482 \\
\hline SHAB02 & 15 & Sphyrna zygaena & Anstey's Beach & $29.55 \mathrm{~S} 31.01 \mathrm{E}$ & $11 / 2002$ & GQ369498 \\
\hline CHAM01 & 17 & Sphyrna lewini & Amanzimtoti & $30.03 \mathrm{~S} 30.53 \mathrm{E}$ & 07/1998 & GQ369503 \\
\hline RTSB01 & 11 & Carcharias taurus & Scottburgh & $30.17 \mathrm{~S} 30.45 \mathrm{E}$ & $11 / 2002$ & GQ369490 \\
\hline SFSR01 & 9 & Isurus oxyrinchus & Salt Rock & 29.30S 31.15E & $11 / 2002$ & GQ369494 \\
\hline RTRB08 & 10 & Carcharias taurus & Richards Bay & $28.48 \mathrm{~S} 32.06 \mathrm{E}$ & 11/1997 & GQ369485 \\
\hline GWUM02 & 18 & Carcharodon carcharias & Umhlanga Rocks & $29.43 \mathrm{~S} 31.05 \mathrm{E}$ & $11 / 2000$ & GQ369477 \\
\hline CSMG01 & 7 & Carcharhinus brachyurus & Margate & $30.52 \mathrm{~S} 30.21 \mathrm{E}$ & $11 / 2004$ & GQ369504 \\
\hline SFSR03 & 9 & Isurus oxyrinchus & Salt Rock & $29.30 \mathrm{~S} 31.15 \mathrm{E}$ & $11 / 2002$ & GQ369496 \\
\hline RTRB12 & 19 & Carcharias taurus & Richards Bay & $28.48 \mathrm{~S} 32.06 \mathrm{E}$ & 11/1999 & GQ369489 \\
\hline GWRB02 & 4 & Carcharodon carcharias & Richards Bay & $28.48 \mathrm{~S} 32.06 \mathrm{E}$ & $10 / 2002$ & GQ369472 \\
\hline
\end{tabular}

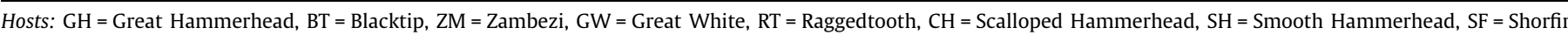

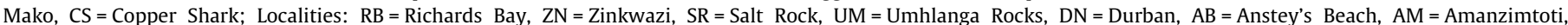
$\mathrm{SB}=$ Scottburgh, $\mathrm{MG}=$ Margate, $\mathrm{LB}=$ Leisure Bay, $\mathrm{PE}=$ Port Edward, MZ = Mzamba. 
occurring sympatrically, both on individual hosts and from the same geographical area (Øines and Heuch, 2005; Øines and Schram, 2008).

This is the first report of an intraspecific phylogenetic study of the cosmopolitan $N$. orientalis based on COI DNA sequences. We sampled the copepods from a range of elasmobranch hosts off a $324 \mathrm{~km} \mathrm{sec}-$ tion of the east coast of South Africa (Dudley and Cliff, 1993). Multiple copepods were analysed from the same host individuals; from multiple individuals of the same host species caught at the same locality but at different times; from the same host species caught at different localities along the coast; and from a range of shark species. Our aim was to determine intraspecific differentiation and whether geographic distance and/or host species affected the extent of differentiation. Given the cosmopolitan distribution of the species and the range of highly mobile shark hosts, from which the species has been recorded, one might hypothesize that passive dispersal by free-living life stages, in addition to shark host movements, may lead to genetic homogeneity among the symbionts.

\section{Materials and methods}

\subsection{Selection of material}

Nesippus orientalis individuals were collected from various sharks caught in the nets of the Natal Sharks Board along the KwaZulu-Natal coast of South Africa over a period of 10 years

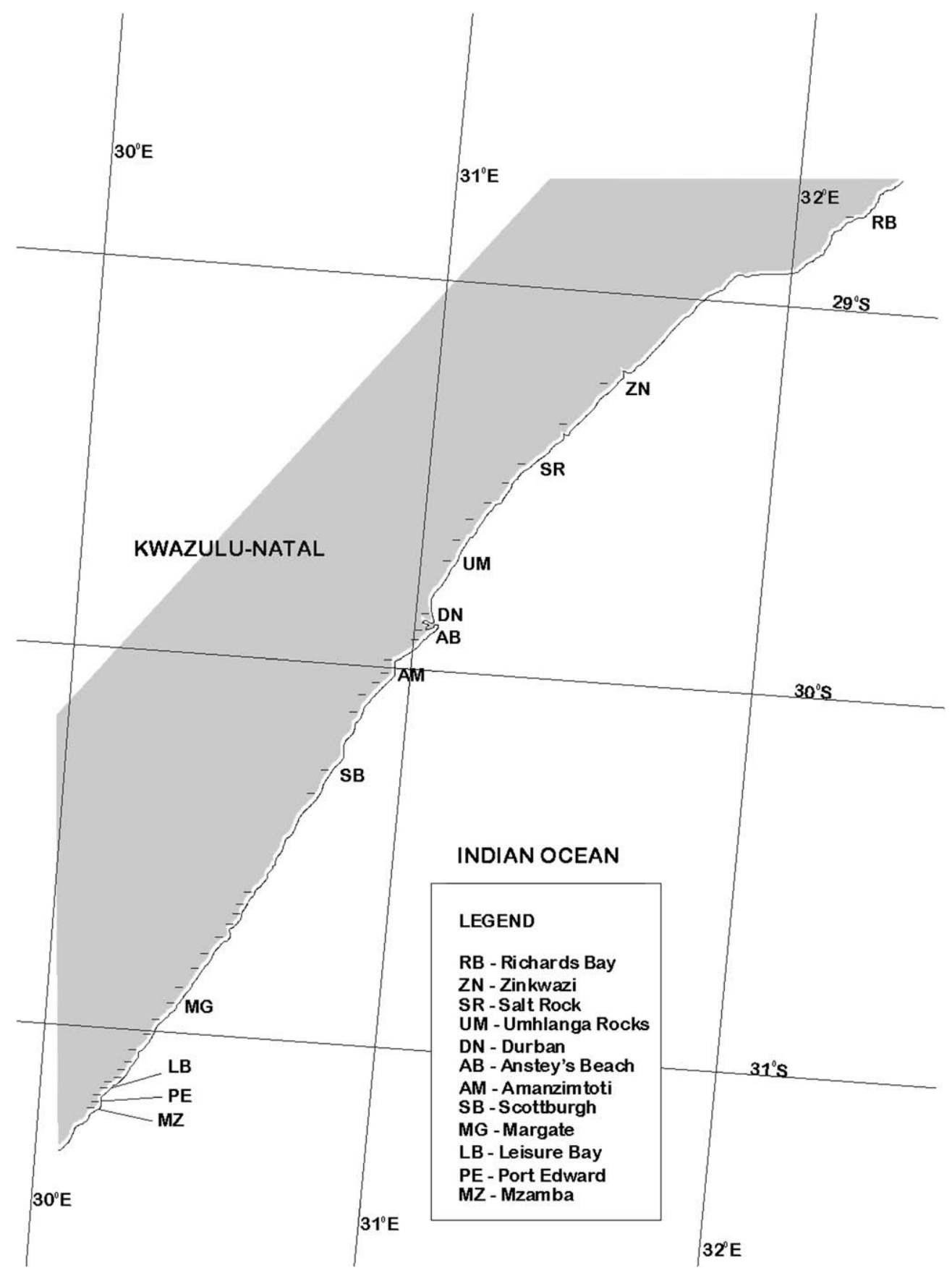

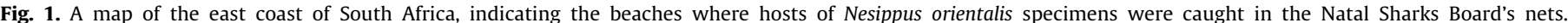

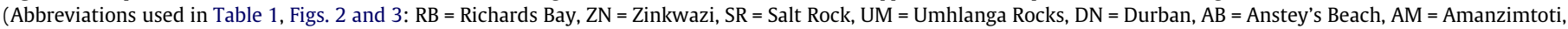
$\mathrm{SB}=$ Scottburgh, $\mathrm{MG}=$ Margate, $\mathrm{LB}=$ Leisure Bay, $\mathrm{PE}=$ Port Edward, MZ = Mzamba.) 
(Table 1, Fig. 1). Collected specimens were preserved in 70\% EtOH. Female specimens of $N$. orientalis were selected from each of nine different host species (i.e. Carcharodon carcharias Linnaeus, 1758; Isurus oxyrinchus Rafinesque, 1810; Carcharias taurus Rafinesque, 1810; Carcharhinus brachyurus Günter, 1870; C. limbatus Valenciennes, in Müller and Henle, 1839; C. leucas Valenciennes, 1839; Sphyrna lewini Griffith and Smith, in Cuvier, Griffith and Smith, 1834; S. mokarran Rüppell, 1837 and S. zygaena Linnaeus, 1758), all members of the Galeomorphii, caught at various localities along the KwaZulu-Natal coast (Fig. 1, Table 1). Additionally, female individuals of N. vespa Kirtisinghe, 1964 collected from Rhina ancylostoma Bloch and Schneider, 1801 were selected as outgroup. Host nomenclature and systematics conform to Compagno (1999). A stereomicroscope was used to verify the species identification of the selected individuals according to the presence of dorsal plates on the fourth thoracic segment (Cressey, 1967).

\subsection{DNA extraction}

DNA was extracted using the DNeasy kit for animal tissues according to the manufacturer's instructions (Qiagen) and with final elution using $\mathrm{ddH}_{2} \mathrm{O}$.

\subsection{Polymerase chain reaction}

The partial mitochondrial COI gene was amplified via the polymerase chain reaction (PCR) (Saiki et al., 1988), using the primers LCO1490 and HCO2198 (Folmer et al., 1994). Two microlitres of the diluted DNA solution was added to a $25 \mu$ PCR reaction containing: 1X Taq buffer, 2.5-4 mM $\mathrm{MgCl}_{2}, 2 \mathrm{mM}$ dNTPs (Promega), 12.5 pmol of each primer and $0.75-1$ units of Supertherm Taq polymerase (Southern Cross Biotechnology) and $\mathrm{ddH}_{2} \mathrm{O}$ to make up the total reaction volume. Cycling parameters in a Geneamp ${ }^{\circledR}$ PCR System 9700 (Applied Biosystems) included the following: an initial denaturation at $95{ }^{\circ} \mathrm{C}(3 \mathrm{~min})$, followed by $35-40$ cycles of $95{ }^{\circ} \mathrm{C}$ (30 s) denaturation, $45-55^{\circ} \mathrm{C}(30 \mathrm{~s})$ annealing and $72{ }^{\circ} \mathrm{C}(45 \mathrm{~s})$ extension. A final extension at $72{ }^{\circ} \mathrm{C}(5 \mathrm{~min})$ completed the amplification. Amplified samples were refrigerated.

Five microlitres of PCR products were electrophoresed through a $1.5 \%$ agarose gel and visualized with ethidium bromide under ultraviolet light. PCR products were purified using ethanol/ammonium acetate precipitation or the High Pure ${ }^{\mathrm{TM}}$ PCR Product Purification Kit (Boehringer Mannheim). Purified products were eluted in $\mathrm{ddH}_{2} \mathrm{O}$.

\subsection{Sequencing}

Cycle sequencing was performed in $10 \mu \mathrm{l}$ volumes, containing approximately $100 \mathrm{ng}$ of purified DNA as template, 1.6-3.2 pmol primer (either LCO1490 or HCO2198) and $2 \mu \mathrm{l}$ of ABI PRISM Big Dye Terminator Cycle Sequencing Ready Reaction Kit (Applied Biosystems). Cycle sequencing was performed in a Geneamp ${ }^{\circledR}$ PCR System 9700 and nucleotide sequences were determined through an ABI 3100 automated sequencer (Applied Biosystems). Sequences were generated once from both strands of DNA and the consensus of each individual was obtained through alignment and inspection in Sequence Navigator 1.01 (Applied Biosystems). No ambiguous bases were identified. Consensus sequences were aligned, under default settings, using Clustal X (Thompson et al., 1997). Nucleotide sequences were unambiguously translated to amino acid sequences using MacClade 4.0 (Maddison and Maddison, 2001) and thus confirmed as of mitochondrial origin. Longer sequences were trimmed so that all sequences used in the analyses were of equal length. Sequences were deposited in GenBank under accession numbers GQ369463-GQ369507.

\subsection{Analyses}

Unique mtDNA haplotypes were identified by constructing a haplotype network following a statistical parsimony approach as implemented in TCS version 1.21 (Clement et al., 2000), based on 95\% confidence of connections among haplotypes (Templeton et al., 1992). The analysis inferred an ancestral allele according to coalescence theory (Crandall and Templeton, 1993). Tajima's test for neutrality (Tajima, 1989) and indices of DNA polymorphism, i.e. haplotype (Nei, 1987) and nucleotide diversity (Tajima, 1983), were estimated in DnaSP version 4 (Rozas et al., 2003).

Phylogenetic analyses included representatives of the divergent lineages identified within $N$. orientalis (two haplotypes from clade I and four haplotypes of clade II), as well as sequences generated for N. vespa (GQ369506 and GQ369507) in the present study. The following outgroup sequences from GenBank were also included for comparative purposes: Nesippus crypturus (FJ447379) and representatives of the sister group Caligidae (Huys et al., 2007; Dippenaar, in press), i.e. Caligus diaphanus (EF065616), C. clemensi (AM235887), C. elongatus (AY386273), Lepeophtheirus salmonis (EU288263), L. pectoralis (AY861364) and L. hippoglossi (AY861362). Uncorrected pairwise genetic distances among the taxa were estimated in PAUP version $4^{*}$ (Swofford, 2002). Model parameters, such as base frequencies, Ti:Tv ratio, proportion of invariable sites (I) and the $\alpha$ value of the gamma distribution (rate variation among sites) were estimated as part of a maximum likelihood (Felsenstein, 1981) search in PAUP. The estimated parameters were used in a neighbour-joining (Saitou and Nei, 1987) and maximum likelihood estimation of phylogenetic relationships using PAUP*. Bootstrap (Felsenstein, 1985) support for nodes was based on 1000 replicates.

Bayesian inference was conducted using MrBayes 3.1.2 (Ronquist and Huelsenbeck, 2003). We used random starting trees and flat priors. Two independent MCMC runs of 1 million generations were done and split frequencies recorded every 1000th generation. This stabilized at 0.003 indicating convergence. Tree sampling was done every 100th generation and a burn-in of 1000 sampled trees ensured sampling from the region of stationarity.

\section{Results}

Not all DNA extractions or PCR amplifications were successful. Since some copepods were collected from hosts that were caught, frozen and defrosted again, it may have resulted in the degeneration of the copepod DNA thus resulting in unsuccessful DNA extraction. The final data set comprised 43 ingroup sequences of 525 nucleotides, with 114 variable sites defining 35 unique haplotypes (Fig. 2). Transitions accounted for about $68 \%$ of the variable sites, with three sites having both a transition and transversion. Substitution ratios at the different codon positions were $10.5 \%$ (1st), $0.9 \%$ (2nd) and $88.6 \%$ (3rd), respectively. Most of the substitutions occurring among the ingroup were synonomous with only two non-synonomous substitutions. A first codon position transition occurred in SFSR03 from GGG to AGG at position 61 resulting in a change in the coded amino acid from Glycine to Serine. RTRB05 had a second codon position transversion from GTG to GGG in position 74, changing the coded amino acid from Valine to Glycine.

Tajima's test was non-significant $(P>0.1)$. Overall, haplotype $(h=0.988, \quad \mathrm{SD}=0.009)$ and nucleotide diversity $(\pi=6.47 \%$, $\mathrm{SD}=1.2 \%$ ) estimates were high, indicating considerable diversity within this wide-ranging species over the range sampled off the South African coast. The TCS analysis could join haplotypes separated by a maximum of nine steps based on the $95 \%$ confidence criterion. The most striking observation from the haplotype network 


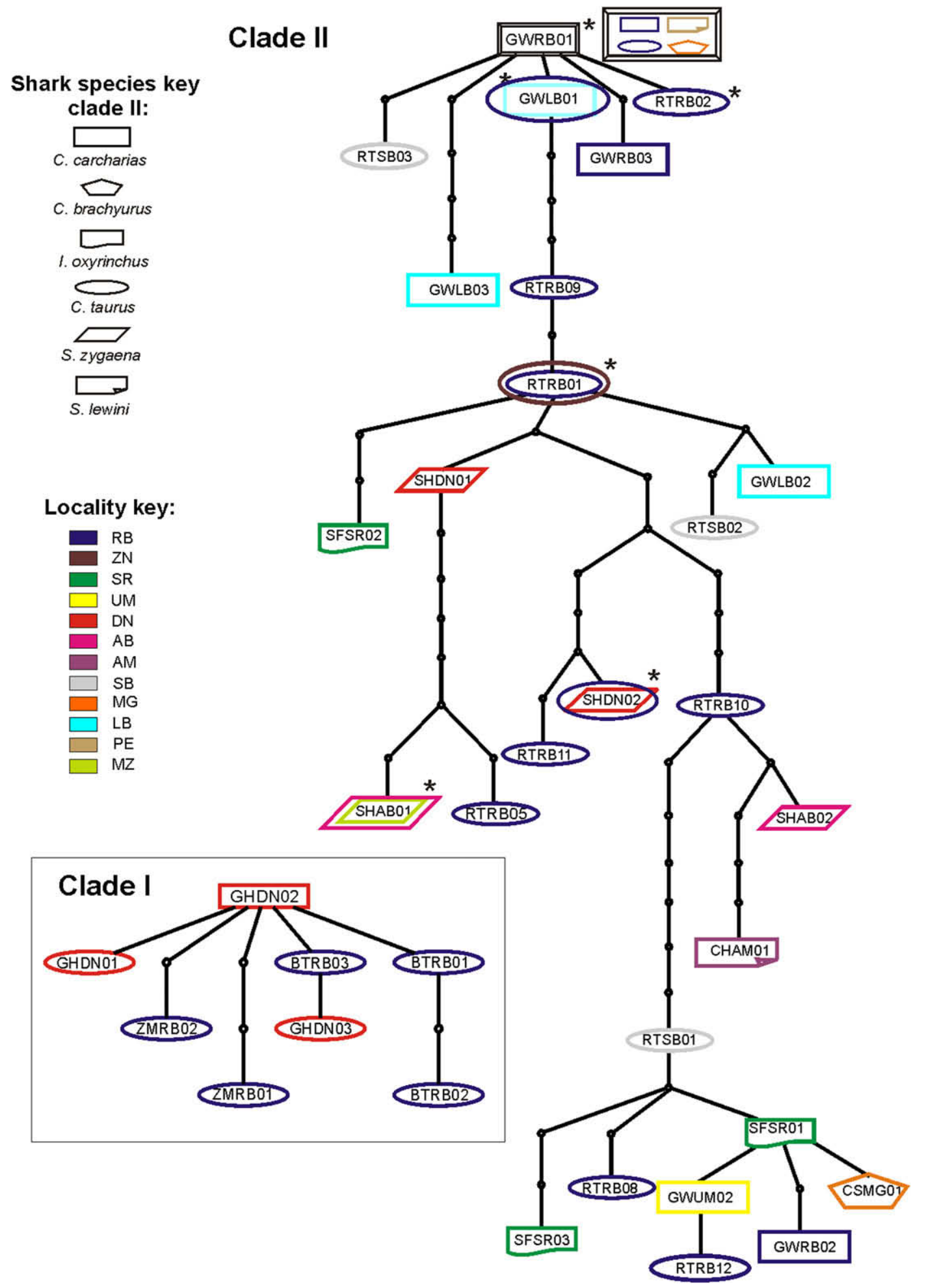

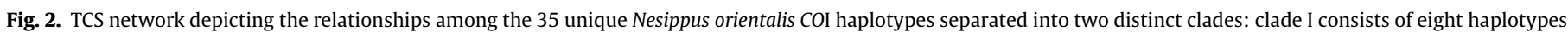
from eight individuals and three different hosts (S. mokarran, C. limbatus, C. leucas); clade II consists of 27 haplotypes from 35 individuals collected from six different shark hosts (S. lewini, S. zygaena, C. brachyurus, I. oxyrinchus, C. taurus and C. carcharias). Each connecting line represents a single mutational change and small circles represent unsampled or extinct haplotypes. Sampling localities (see Fig. 1) are colour coded for both clades. For clade II, the different shark species are distinguished by different shapes for each detected Nesippus haplotype. Shared haplotypes are indicated by asterisks.

was the presence of two divergent clades that could not be joined with confidence by the TCS analysis: clade I comprised eight haplotypes, represented by copepods $(n=8)$ collected from Great hammerhead (Sphyrna mokarran), Blacktip (Carcharhinus limbatus) and Zambezi (C. leucas) shark hosts from Durban and Richards Bay (central and northern KwaZulu-Natal coast); clade II comprised 27 haplotypes, including individuals $(n=35)$ collected from throughout the sampled region from six different shark hosts (Scalloped hammerhead (Sphyrna lewini), Smooth hammerhead ( $S$. zygaena), Copper shark (Carcharhinus brachyurus), Shortfin mako 
(Isurus oxyrinchus), Raggedtooth (Carcharias taurus) and Great white (Carcharodon carcharias)). Diversity within the two clades was high in terms of haplotype diversity (clade I $h=1$; clade II $h=0.982$ ) indicating few shared alleles, while relatively low levels of nucleotide diversity (clade I $\pi=0.59 \%$; clade II $\pi=1.47 \%$ ) were estimated.

All individuals within clade I had unique haplotypes. Within clade II there were only a few instances of haplotype sharing, i.e. the inferred ancestral haplotype GWRB01 $(n=4)$ was shared by individuals from a Great white and Raggedtooth from Richards Bay, a Scalloped hammerhead from Port Edward and a Copper shark from Margate (north and south coasts); haplotype GWLB01 $(n=2)$ was recorded from a Great white caught off Leisure Bay and a Raggedtooth from Richards Bay (north and south coasts); RTRB02 $(n=2)$ from the same Raggedtooth host individual from Richards Bay; RTRB01 $(n=2)$ was represented by copepods from Raggedtooth sharks from Richards Bay and Zinkwazi (north coast); SHDN02 $(n=2)$ was recorded from a Smooth hammerhead from Durban and a Raggedtooth from Richards Bay and SHAB01 $(n=2)$ from Smooth hammerheads from Anstey's Beach and Mzamba. Neither the pattern of haplotype sharing, nor the relationships among haplotypes within clade II, appeared to be associated with the geographic location of the shark specimen, with particular host species, the particular sampled host individual, or with the sampling date (Fig. 2, Table 1).

In the final data set there were 12 instances, where 2 or 3 individuals from the same host individual were analysed (Table 1). Some of these copepods were genetically quite similar, especially in clade I (average number of mutations among copepods from the same host individual $=2.7$ steps). In clade II there were, however, several instances, where genetically distinctive haplotypes were sampled from the same host individual (10-28 mutational steps, see Fig. 2).

The uncorrected sequence divergence estimates among the five selected haplotypes (representing the two clades) and the outgroup taxa are summarized in Table 2 . In contrast to the estimates within the two clades (clade I, $0.8 \%$; clade II $0.8-2.5 \%$ ), the divergence between the two $N$. orientalis clades (average divergence 17.44\%) was within the same range as among the three Nesippus species ( 16.5-22.3\%), as well as among the three species of both Caligus and Lepeophtheirus ( 17-19.3\%).

Model parameters were as follows: base frequencies $(A=0.26$, $C=0.13, G=0.18, C=0.43$ ); $\mathrm{Ti} / \mathrm{Tv}$ ratio 6.69 ; proportion of invariable sites 0.49 and $\alpha=0.51$, indicating some rate heterogeneity among sites. The phylogenetic analyses yielded congruent topologies in most respects. However, the relationships among the Nesippus species, including the two clades within $N$. orientalis, were unresolved in the ML topology while both ML and NJ clustered C. diaphanus and C. elongatus as sister taxa. Only the Bayesian phylogram is presented in Fig. 3, but the NJ and ML support values are also indicated. From the sequence divergence estimates and their reciprocal monophyly in the phylogeny (78\% NJ bootstrap support, 1.0 posterior probability), clades I and II within $N$. orientalis appeared to represent two distinct sister lineages.

\section{Discussion}

The overall diversity of $N$. orientalis individuals, along the sampled area of the east coast of KwaZulu-Natal, is high as it is evident from the relatively high estimates of the haplotype $(h=0.988)$ and nucleotide ( $\pi=6.47 \%$ ) diversities. This may be indicative of a stable population with a large long-term effective population size or an admixed sample of individuals from historically separated populations (Avise, 2000), subjected to drift and limited gene flow.

However, according to the haplotype network (Fig. 2) and the phylogeny (Fig. 3) the partial $\mathrm{COI}$ sequences examined among $N$. orientalis specimens clearly represent two highly supported and distinct lineages. The divergence between the two clades (17.44\%) is clearly at a level expected for interspecific rather than intraspecific relationships in crustaceans. This value is comparable to the more than $17 \%$ and $18 \%$ sequence divergence between conspecific populations of the harpacticoid copepods, Tigriopus californicus (Burton, 1998; Burton and Lee, 1994, respectively), is lower than that obtained for conspecific populations of Cletocamptus deitersi (25\%) (Rocha-Olivares et al., 2001), but higher than the comparable K2P distance for conspecific populations of the siphonostomatoid Caligus elongatus (12\%) (Øines and Schram, 2008). Sequence divergence of $16-22 \%$ exists between previously defined Nesippus species (Table 2) which agrees with previous findings of $13-22 \%$ sequence divergence in congeneric species of copepods (Bucklin et al., 1999). Therefore, clades I and II probably represent separate species under the phylogenetic species concept. Even with the more than 17\% divergence between the two clades of $N$. orientalis individuals, no amino acid substitutions occurred between the two clades with two amino acid substitutions occurring within clade II (0.8-2.5\% divergence). Isofemale lines of T. californicus showed $15.4 \%$ divergence which all constituted synonomous substitutions (Burton and Lee, 1994), while Burton (1998) found only two amino acid substitutions between populations with a $22 \%$ divergence. From this it is clear that the sequence divergence and number of amino acid substitutions are probably not related and does not agree with Lefébure et al. (2006) that there is mostly no amino acid divergence within species. These

Table 2

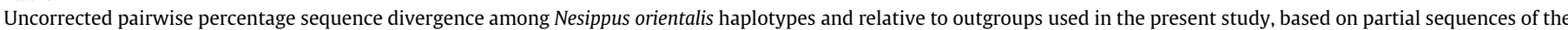

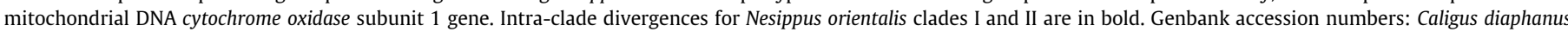

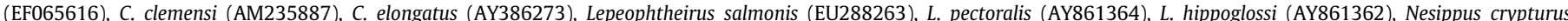
(FJ447379), N. vespa (GQ369507), GHDN02 (GQ369463), ZMRB01 (GQ369469), RTZN01 (GQ369493), GWRB01 (GQ369471), SHAB01 (GQ369497), RTSB01 (GQ369490).

\begin{tabular}{|c|c|c|c|c|c|c|c|c|c|c|c|c|c|c|c|}
\hline & & 1 & 2 & 3 & 4 & 5 & 6 & 7 & 8 & 9 & 10 & 11 & 12 & 13 & 14 \\
\hline 1 & L. salmonis & - & & & & & & & & & & & & & \\
\hline 2 & L. pectoralis & 18.18 & - & & & & & & & & & & & & \\
\hline 3 & L. hippoglossi & 19.45 & 17.18 & - & & & & & & & & & & & \\
\hline 4 & C. diaphanus & 21.92 & 20.52 & 19.56 & - & & & & & & & & & & \\
\hline 5 & C. clemensi & 19.77 & 20.85 & 16.82 & 17.00 & - & & & & & & & & & \\
\hline 6 & C. elongatus & 22.49 & 23.40 & 22.36 & 19.29 & 18.75 & - & & & & & & & & \\
\hline 7 & N. crypturus & 21.45 & 22.74 & 18.65 & 19.96 & 16.82 & 22.54 & - & & & & & & & \\
\hline 8 & N. vespa & 20.83 & 20.56 & 22.72 & 21.12 & 20.02 & 22.43 & 18.24 & - & & & & & & \\
\hline 9 & GHDN02 & 21.97 & 22.52 & 18.44 & 21.89 & 20.29 & 21.94 & 16.45 & 17.71 & - & & & & & \\
\hline 10 & ZMRB01 & 22.40 & 22.73 & 19.03 & 22.09 & 20.68 & 22.14 & 16.47 & 17.93 & 0.81 & - & & & & \\
\hline 11 & RTZN01 & 24.61 & 24.08 & 23.45 & 21.66 & 21.87 & 24.55 & 18.79 & 22.14 & 17.51 & 17.77 & - & & & \\
\hline 12 & GWRB01 & 24.43 & 23.81 & 23.05 & 21.19 & 22.18 & 24.65 & 18.40 & 21.17 & 17.09 & 17.33 & 0.80 & - & & \\
\hline 13 & SHAB01 & 25.31 & 23.27 & 23.09 & 21.01 & 23.31 & 25.28 & 18.60 & 22.28 & 17.41 & 17.64 & 1.93 & 2.21 & - & \\
\hline 14 & RTSB01 & 24.07 & 24.20 & 22.85 & 21.68 & 22.67 & 24.80 & 18.23 & 22.28 & 17.25 & 17.48 & 1.13 & 1.26 & 2.53 & - \\
\hline
\end{tabular}




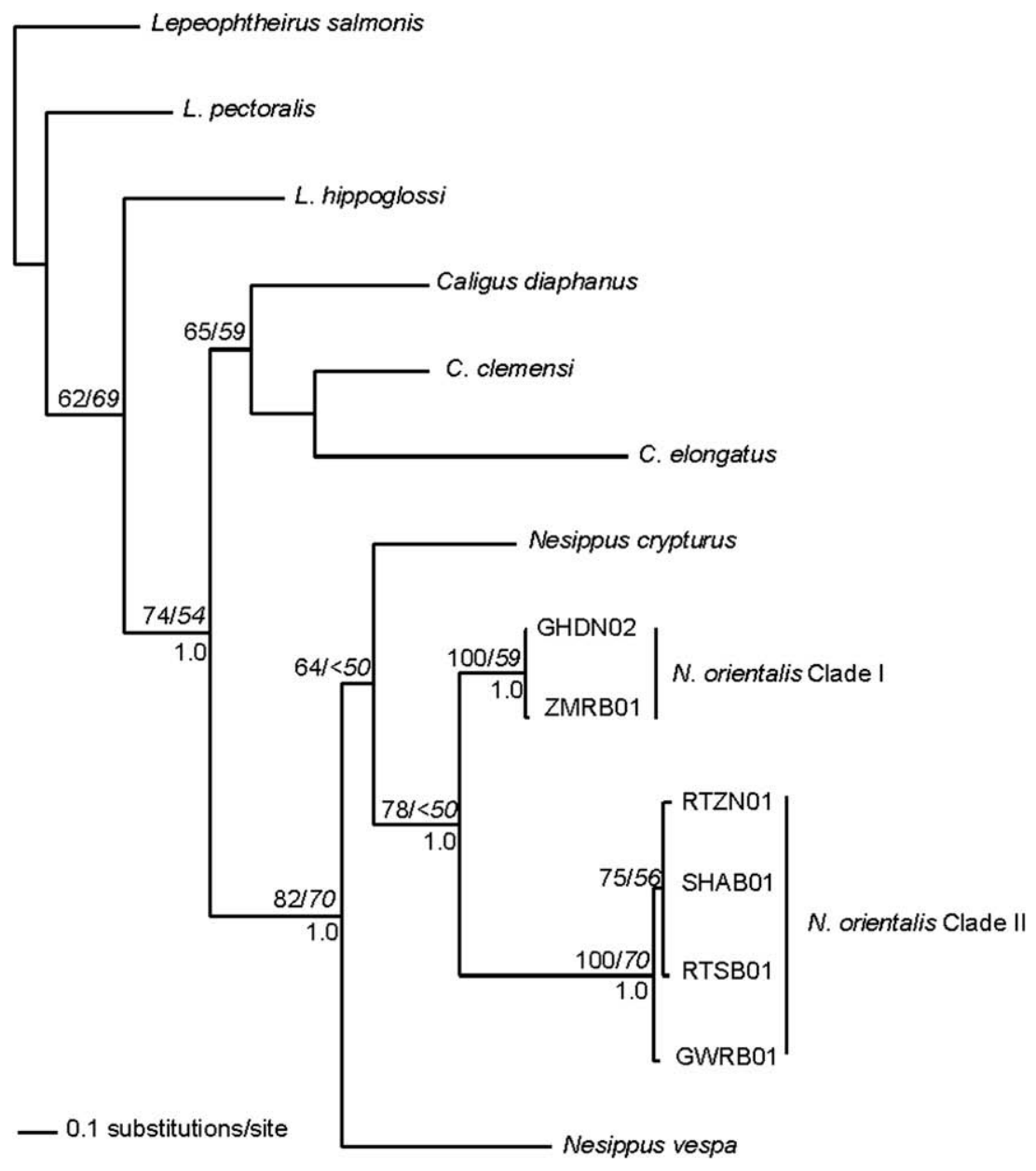

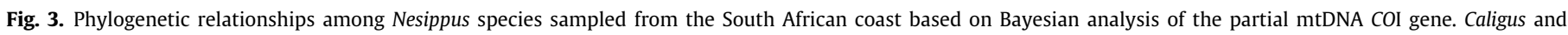

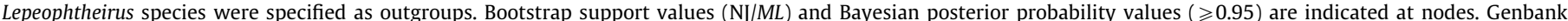

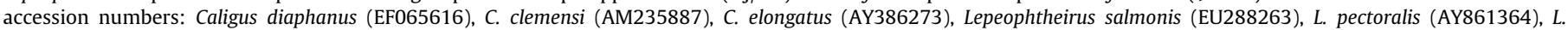

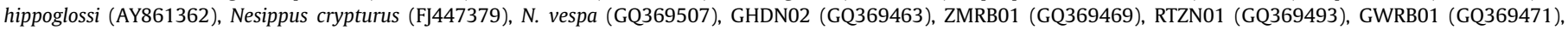
SHAB01 (GQ369497), RTSB01 (GQ369490).

findings, together with the knowledge that most genetic analyses of species boundaries in Crustacea confirm or reveal the existence of cryptic species (Knowlton, 2000), necessitate a thorough morphological re-examination of $N$. orientalis specimens collected from S. mokarran, C. limbatus and C. leucas. Morphological information obtained from such a study will establish whether individuals in clade II indeed represent a cryptic/sibling species or rather a pseudo-sibling species (i.e. due to inadequate study of morphological features (Knowlton, 1993)) to those in clade I. If indeed these are cryptic species, one is likely not to observe any morphological differences.

The distinction between the two lineages was not related to locality or date of capture. Specimens of clade I were collected from hosts belonging to two different families, i.e. Carcharhinidae ( $C$. limbatus and C. leucas caught during 2002 at Richards Bay) and Sphyriidae (S. mokarran caught during 2000 at Durban) (Fig. 2, Table 1). Specimens of clade II were collected from hosts representing four different families, i.e. Odontaspididae (C. taurus caught during 1997 and 1999 at Richards Bay, at Zinkwazi during 1998 and at Scottburgh during 2002); Lamnidae (I. oxyrinchus caught during 2002 at Salt Rock and C. carcharias caught during 1999 at Richards Bay, at Umhlanga Rocks during 2000 and at Leisure Bay during 2002); Carcharhinidae (C. brachyurus caught at Margate during 2004), and Sphyriidae (S. lewini caught during 1998 at Amanzimtoti and Port Edward, and S. zygaena caught during 1995 at Mzamba and at Durban and Anstey's Beach during 2002). Although there was overlap between the host ranges of the copepods with respect to the shark families that the two clades were recorded from, there appears to be host selection differences between the copepods from the two lineages. Future research should focus on providing a more detailed assessment of the distribution and host range of the two lineages and if host behavioural differences may impact host selection. This may be possible since it is presumed that the currents caused by the movements or respiration of hosts are among the factors directing a copepod to them, while chemoreception may be involved on the part of the copepod (Kabata, 1981). Even though factors that limit species distributions might also be expected to demarcate genetically distinct lineages within species (Burton, 1998), no such factors are currently known for $N$. orientalis individuals.

Fairly high diversity levels were found within each clade (clade I $h=1$; clade II $h=0.982$ ) with no shared haplotypes in clade I and only a few shared haplotypes in clade II and relatively low levels of nucleotide diversity (clade I $\pi=0.59 \%$; clade II $\pi=1.47 \%$ ). This may be indicative of rapid population growth from an ancestral population with a small effective population size which had sufficient time for the recovery of the haplotype variation through mutation (Avise, 2000). Haplotype relationships within the two clades did not appear to follow an easily identifiable pattern. For example, four specimens collected from four different hosts, from three different localities on the north and south coast during four different years, shared the same haplotype (the inferred ancestral 
haplotype of clade II, see Fig. 2, Table 1). The sharing of the ancestral haplotype (GWRB01) specifically and haplotypes GWLB01 and RTRB01 could reflect the retention of ancestral polymorphisms since they were more central haplotypes in the network, while the sharing of haplotypes RTRB02, SHDN02 and SHAB01 could indicate recent dispersal due to the short free-living stage and/or host movements and interactions. It is, however, also possible that more extensive sampling, especially the analyses of more individuals from the same host individuals, may reveal more instances of shared haplotypes and haplotype frequency differences as observed in other siphonostomatoid parasites (see for example Øines and Heuch, 2007).

The diversity within the two clades (average divergence $=\sim 1.6 \%$ ) was an order of magnitude less than that estimated between them, but the level of differentiation within the clades compares well with previous studies. It is higher than that found among isofemale lines of $T$. californicus from six populations $(<1 \%)$ (Burton and Lee, 1994) and among geographically separated populations of Calanus helgolandicus (0.5-0.8\%) (Hill et al., 2001), similar to that found within each type of Cletocamptus deitersi (0.2-1.7\%) (Rocha-Olivares et al., 2001) and less than that among conspecific Pseudocalanus individuals $( \pm 2 \%)$ and between Calanus pacificus subspecies (3\%) (Hill et al., 2001). These values confirm previous conclusions by Avise (2000) and Waugh (2007) that the general intraspecific divergence in mitochondrial genes (specifically $\mathrm{COI}$ ) is usually less than $1 \%$ and rarely more than $2 \%$, while intraspecific variation is generally less than $10 \%$ of that observed between species.

Understanding of processes underlying phylogeographic patterns requires extensive temporal and spatial sampling. However, in populations of $T$. californicus phylogeographic patterns were more adequately described using few sequences from many populations than it would have been using many sequences from few populations (Burton, 1998). The current sampling was sufficient to indicate high diversity and the possible existence of cryptic species in $N$. orientalis individuals. More extensive sampling may be needed to attempt to understand the processes underlying this diversity. However, increased sampling of $\mathrm{N}$. orientalis specimens from more hosts, will be exceptionally daunting, given the life history of $N$. orientalis and the need for destructive sampling of hosts. Furthermore, doing laboratory crossings between individuals from the two lineages to determine whether they are reproductively isolated, will be impossible due to their hosts and infection site on the hosts. Therefore, determining the taxonomic position of the two lineages will have to rely on morphology and sequence divergence. The partial $\mathrm{COI}$ gene sequenced in the current study proved to be efficient in distinguishing diversity on the intraspecific and interspecific levels. However, even though species delimitation based on $\mathrm{COI}$ alone is done as part of DNA barcoding (Hebert et al., 2003; Waugh, 2007) it is imperfect and should be combined with at least one nuclear gene to be more robust (Lefébure et al., 2006).

\section{Acknowledgments}

The authors thank the Natal Sharks Board and Department of Biodiversity at the University of Limpopo (UL) for field and laboratory support and the Research and Development Administration (UL) for financial support. This research was supported by the University of Pretoria through the provision of laboratory and analytical facilities and by National Research Foundation (NRF) funding to P.B. Any opinion, findings and conclusions or recommendations expressed herein are those of the authors and therefore the NRF does not accept any liability in regard thereto.

\section{References}

Anstensrud, M., 1990. Mating strategies of two parasitic copepods [(Lernaeocera branchialis (L.) (Pennellidae) and Lepeophtheirus pectoralis (Müller) (Caligidae)] on flounder: polygamy, sex-specific age at maturity and sex ratio. Journal of Experimental Marine Biology and Ecology 136, 141-158.

Avise, J.C., 2000. Phylogeography: The History and Formation of Species. Havard University Press, London.

Boxshall, G.A., 1974. The population dynamics of Lepeophtheirus pectoralis (Müller): seasonal variations in abundance and age structure. Parasitology 69, 361-371.

Boxshall, G.A., Halsey, S.H., 2004. An Introduction to Copepod Diversity. The Ray Society, London.

Bucklin, A., Guarnieri, M., Hill, R.S., Bentley, A.M., Kaartvedt, S., 1999. Taxonomic and systematic assessment of planktonic copepods using mitochondrial $\mathrm{CO}$ sequence variation and competitive species-specific PCR. Hydrobiologia 401 239-254.

Burton, R.S., 1998. Intraspecific phylogeography across the point conception biogeographic boundary. Evolution 52, 734-745.

Burton, R.S., Lee, B.-N., 1994. Nuclear and mitochondrial gene genealogies and allozyme polymorphism across a major phylogeographic break in the copepod Tigriopus californicus. Proceedings of the National Academy of Sciences of the United States of America 91, 5197-5201.

Clement, M., Posada, D., Crandall, K.A., 2000. TCS: a computer program to estimate gene genealogies. Molecular Ecology 9, 1657-1659.

Compagno, L.J.V., 1999. An overview of Chondrichthyan systematics and biodiversity in southern Africa. Transactions of the Royal Society of South Africa 54, 75-120.

Crandall, K.A., Templeton, A.R., 1993. Empirical tests of some predictions from coalescence theory with applications to intraspecific phylogeny reconstruction. Genetics 134, 959-969.

Cressey, R., 1967. Revision of the family Pandaridae (Copepoda: Caligoida). Proceedings of the United States National Museum 121, 1-33.

Cressey, R.F., 1970. Copepods parasitic on sharks from the west coast of Florida Smithsonian Contributions to Zoology 38, 1-30.

De Meeüs, T., Marin, R., Renaud, F., 1992. Genetic heterogeneity within populations of Lepeophtheirus europaensis (Copepoda: Caligidae) parasitic on two host species. International Journal for Parasitology 22, 1179-1181.

Dippenaar, S.M., 2004. Reported siphonostomatoid copepods parasitic on marine fishes of southern Africa. Crustaceana 77, 1281-1328.

Dippenaar, S.M., 2009. Estimated molecular phylogenetic relationships of six siphonostomatoid (Copepoda) families symbiotic on elasmobranchs. Crustaceana, 82.

Dippenaar, S.M., Jordaan, B.P., 2006. Nesippus orientalis Heller, 1868 (Pandaridae: Siphonostomatoida): descriptions of the adult, young and immature females, a first description of the male and aspects of their functional morphology. Systematic Parasitology 65, 27-41.

Dudley, S.F.J., Cliff, G., 1993. Trends in catch rates of large sharks in the Natal meshing program. In: Pepperell, J., West, J., Woon, P. (Eds.), Shark Conservation. Proceedings of an International Workshop on the Conservation of Elasmobranchs, Taronga Zool, Sydney, Australia, pp. 59-70.

Felsenstein, J., 1981. Evolutionary trees from DNA sequences: a maximum likelihood approach. Journal of Molecular Evolution 17, 368-376.

Felsenstein, J., 1985. Confidence limits on phylogenies: an approach using the bootstrap. Evolution 39, 783-791.

Folmer, O., Black, N., Hoeh, W., Lutz, R., Vrijenhoek, R., 1994. DNA primers for amplification of mitochondrial cytochrome $c$ oxidase subunit I from diverse metazoan invertebrates. Molecular Marine Biology and Biotechnology 3, 294299.

Hebert, P.D.N., Ratnasingham, S., Dewaard, J.R., 2003. Barcoding animal life: cytochrome $c$ oxidase subunit 1 divergences among closely related species. Proceedings of the Royal Society, London B 270 (Suppl.), S96-S99.

Hill, R.S., Allen, L.D., Bucklin, A., 2001. Multiplexed species-specific PCR protocol to discriminate four N. Atlantic Calanus species, with an mtDNA gene tree for ten Calanus species. Marine Biology 139, 279-287.

Huys, R., Llewellyn-Hughes, J., Conroy-Dalton, S., Olson, P.D., Spinks, J.N., Johnston, D.A., 2007. Extraordinary host switching in siphonostomatoid copepods and the demise of the Monstrilloida: integrating molecular data, ontogeny and antennulary morphology. Molecular Phylogenetics and Evolution 43, 368-378.

Kabata, Z., 1981. Copepoda (Crustacea) parasitic on fishes: problems and perspectives. In: Lumsden, W.H.R., Muller, R., Baker, J.R. (Eds.), Advances in Parasitology, vol. 19. Academic Press, London, pp. 1-71.

Knowlton, N., 1993. Sibling species in the sea. Annual Review of Ecology and Systematics 24, 189-216.

Knowlton, N., 2000. Molecular genetic analyses of species boundaries in the sea Hydrobiologia 420, 73-90.

Lefébure, T., Douady, C.J., Gouy, M., Gibert, J., 2006. Relationship between morphological taxonomy and molecular divergence within Crustacea: proposal of a molecular threshold to help species delimitation. Molecular Phylogenetics and Evolution 40, 435-447.

Lin, C.-L., Ho, J.-S., 1993. Life history of Caligus epidemicus Hewitt parasitic on tilapia (Oreochromis mossambicus) cultured in brackish water. In: Boxshall, G.A., Defaye, D. (Eds.), Pathogens of Wild and Farmed Fish: Sea Lice. Ellis Horwood London, pp. 5-15.

Maddison, D.R., Maddison, W.P., 2001. MacClade v.4, Analysis of Phylogeny and Character Evolution. Sinauer Associates, Sunderland, MA. 
Nei, M., 1987. Molecular Evolutionary Genetics. Columbia University Press, New York.

Øines, Ø., Heuch, P.A., 2005. Identification of sea louse species of the genus Caligus using mtDNA. Journal of the Marine Biological Association, United Kingdom 85, 73-79.

Øines, Ø., Heuch, P.A., 2007. Caligus elongatus Nordmann genotypes on wild and farmed fish. Journal of Fish Diseases 30, 81-91.

Øines, Ø., Schram, T., 2008. Intra- or inter-specific difference in genotypes of Caligus elongatus Nordmann, 1832? Acta Parasitologica 53, 93-105.

Rocha-Olivares, A., Fleeger, J.W., Foltz, D.W., 2001. Decoupling of molecular and morphological evolution in deep lineages of a meiobenthic harpacticoid copepod. Molecular Biology and Evolution 18, 1088-1102.

Ronquist, R., Huelsenbeck, J.P., 2003. MrBayes 3: Bayesian phylogenetic inference under mixed models. Bioinformatics 19, 1572-1574.

Rozas, J., Sánchez-Delbarrio, J.C., Messeguer, X., Rozas, R., 2003. DnaSP, DNA polymorphism analyses by the coalescent and other methods. Bioinformatics 19, 2496-2497.

Saiki, R., Gelfand, D.H., Stofell, S., Scharf, S.J., Higuchi, R., Horn, G.T., Mullis, K.B., Erlich, H.A., 1988. Primer-directed enzymatic amplification of DNA with a thermostable DNA polymerase. Science $239,487-491$.

Saitou, N., Nei, M., 1987. A neighbor-joining method: a new method for reconstructing phylogenetic trees. Molecular Biology and Evolution 4, 406-425.

Schram, T.A., 1993. Supplementary descriptions of the developmental stages of Lepeophtheirus salmonis (Krøyer, 1837) (Copepoda: Caligidae). In: Boxshall, G.A., Defaye, D. (Eds.), Pathogens of Wild and Farmed Fish: Sea Lice. Ellis Horwood, London, pp. 30-47.
Shao, R., Barker, S.C., 2007. Mitochondrial genomes of parasitic arthropods: implications for studies of population genetics and evolution. Parasitology 134, 153-167.

Swofford, D.L., 2002. PAUP*: Phylogenetic Analysis using Parsimony (and Other Methods), Version 4.0b10. Sinauer Associates, Sunderland, MA

Tajima, F., 1983. Evolutionary relationship of DNA sequences in finite populations. Genetics 105, 437-460.

Tajima, F., 1989. Statistical method for testing the neutral mutation hypothesis by DNA polymorphism. Genetics 123, 585-595.

Templeton, A., Crandall, K.A., Sing, C.F., 1992. A cladistic analysis of phenotypic associations with haplotypes inferred from restriction endonuclease mapping and DNA sequence data. III. Cladogram estimation. Genetics 132, 619-633.

Thompson, J.D., Gibson, T.J., Plewniak, T.F., Jeanmougin, F., Higgins, D.G., 1997. The Clustal X windows interface: flexible strategies for multiple sequence alignment aided by quality analysis tools. Nucleic Acids Research 24, 4876-4882.

Todd, C.D., 1998. Larval supply and recruitment of benthic invertebrates: do larvae always disperse as much as we believe? Hydrobiologia 375 (376), 1-21.

Todd, C.D., 2007. The copepod parasite (Lepeophtheirus salmonis (Krøyer), Caligus elongatus Nordmann) interactions between wild and farmed Atlantic salmon (Salmo salar L.) and wild sea trout (Salmo trutta L.): a mini review. Journal of Plankton Research 29, i61-i71.

Waugh, J., 2007. DNA barcoding in animal species: progress, potential and pitfalls. Bioessays 29, 188-197.

Wilson, C.B., 1907. North American parasitic copepods belonging to the family Caligidae. Parts 3 and 4. A revision of the Pandarinae and the Cecropinae. Proceedings of the United States National Museum 33, 323-490. 